\title{
Assessment of a respiratory face mask for capturing air pollutants and pathogens including human influenza and rhinoviruses
}

\author{
S. Steve Zhou ${ }^{1}$, Salimatu Lukula ${ }^{1}$, Cory Chiossone ${ }^{1}$, Raymond W. Nims ${ }^{2}$, Donna B. Suchmann ${ }^{1}$, \\ M. Khalid Ijaz,4 \\ ${ }^{1}$ Microbac Laboratories, Sterling, VA, USA; ${ }^{2}$ RMC Pharmaceutical Solutions, Inc., Longmont, CO, USA; ${ }^{3}$ Research and Development, RB, \\ Montvale, NJ, USA; ${ }^{4}$ Medgar Evers College of the City University of New York (CUNY), Brooklyn, NY, USA \\ Contributions: (I) Conception and design: SS Zhou, S Lukula, C Chiossone, DB Suchmann, MK Ijaz; (II) Administrative support: None; (III) \\ Provision of study materials or patients: MK Ijaz; (IV) Collection and assembly of data: SS Zhou, S Lukula, C Chiossone, DB Suchmann; (V) Data \\ analysis and interpretation: RW Nims, SS Zhou, MK Ijaz; (VI) Manuscript writing: All authors; (VII) Final approval of manuscript: All authors. \\ Correspondence to: Dr. M. Khalid Ijaz. RB, One Philips Parkway, Montvale, NJ 07645, USA. Email: khalid.ijaz@rb.com.
}

Background: Prevention of infection with airborne pathogens and exposure to airborne particulates and aerosols (environmental pollutants and allergens) can be facilitated through use of disposable face masks. The effectiveness of such masks for excluding pathogens and pollutants is dependent on the intrinsic ability of the masks to resist penetration by airborne contaminants. This study evaluated the relative contributions of a mask, valve, and Micro Ventilator on aerosol filtration efficiency of a new N95 respiratory face mask.

Methods: The test mask was challenged, using standardized methods, with influenza A and rhinovirus type 14, bacteriophage $\Phi X 174$, Staphylococcus aureus (S. aureus), and model pollutants. The statistical significance of results obtained for different challenge microbial agents and for different mask configurations (masks with operational or nonoperational ventilation fans and masks with sealed Smart Valves) was assessed.

Results: The results demonstrate $>99.7 \%$ efficiency of each test mask configuration for exclusion of influenza A virus, rhinovirus 14, and S. aureus and $>99.3 \%$ efficiency for paraffin oil and sodium chloride (surrogates for $\mathrm{PM}_{2.5}$ ). Statistically significant differences in effectiveness of the different mask configurations were not identified. The efficiencies of the masks for excluding smaller-size (i.e., rhinovirus and bacteriophage $\Phi \mathrm{X} 174)$ vs. larger-size microbial agents (influenza virus, S. aureus) were not significantly different.

Conclusions: The masks, with or without features intended for enhancing comfort, provide protection against both small- and large-size pathogens. Importantly, the mask appears to be highly efficient for filtration of pathogens, including influenza and rhinoviruses, as well as the fine particulates $\left(\mathrm{PM}_{2.5}\right)$ present in aerosols that represent a greater challenge for many types of dental and surgical masks. This renders this individual-use N95 respiratory mask an improvement over the former types of masks for protection against a variety of environmental contaminants including $\mathrm{PM}_{2.5}$ and pathogens such as influenza and rhinoviruses.

Keywords: Aerosol filtration; bacteriophage ФX174; influenza; rhinoviruses; Staphylococcus aureus (S. aureus); airborne pollutants $\left(\mathrm{PM}_{2.5}\right)$

Submitted Nov 30, 2017. Accepted for publication Mar 15, 2018.

doi: $10.21037 /$ jtd.2018.03.103

View this article at: http://dx.doi.org/10.21037/jtd.2018.03.103 


\section{Introduction}

Concern over personal health in the face of airborne assaults in the form of aerosolized pathogens (viruses, bacteria, mycobacteria, non-tuberculous mycobacteria, etc.) and environmental pollutants (allergens and particulates) is high in geographical areas with high morbidity and mortality associated with these pollutants (1-10). Of particular concern is fine particulate matter with an aerodynamic diameter $<2.5 \mu \mathrm{m}$ (referred to as $\mathrm{PM}_{2.5}$ ) that originates from fossil fuel combustion associated with, for instance, coal-fired power plants and traffic.

The potential for infection with airborne pathogens and for exposure to such airborne particulates poses a threat to global public health (9) which can be mitigated through the personal use of disposable face masks. The effectiveness of such masks for excluding pathogens and pollutants is a function both of wearer compliance and comfort (11) and the intrinsic ability of the masks to resist penetration by airborne particulates (such as $\mathrm{PM}_{2.5}$ ) and infectious agents. For instance, the use of protective face masks negatively impacts respiratory and dermal mechanisms of human thermoregulation through impairment of convection, evaporation, and radiation processes (11).

Wearer comfort can be enhanced by a variety of modifications to the masks, including (among others) the addition to the face mask of features such as the Micro Ventilator (comprising a Smart Valve and ventilation fan) (Figure 1). The Micro Ventilator improves the flow of exhaled gas out of the mask (11). The purpose of the one-way Smart Valve is to limit the air flow into the mask through the valve such that all of the air must pass through the filter material. On the other hand, exhaled air may pass out of the mask through the valve. The purpose of the fan is to aid in the removal of exhaled air from the interior of the mask. The Dettol PROTECT ${ }^{+}$Smart Mask Large size (hereafter called the "test mask") (Figure 1) incorporates these features that are designed for the purpose of enhancing wearer comfort (11).

It is important that effectiveness of personal protective devices such as face masks be measured against a variety of relevant pathogens and pollutants, and that this effectiveness be established both while using and rendering inoperable any incorporated comfort-enhancing features. The present studies were designed to assess the ability of different configurations of the test mask (the mask with operating Micro Ventilator, the mask with operating Smart Valve but without Micro Ventilator, and the mask with the Smart Valve covered/sealed) to exclude the penetration of experimentally aerosolized influenza A virus and rhinovirus type 14, phage $\Phi X 174$, and Staphylococcus aureus (S. aureus) and surrogate air pollutants (paraffin oil and sodium chloride) using methods specified in the appropriate Standards [ASTM F2101 (12,13), EN 14683:2014 (14), and EN 149:2001 + A1:2009 (15)].

\section{Methods}

\section{Viruses and cell lines}

Influenza $\mathrm{A}(\mathrm{H} 1 \mathrm{~N} 1)$ virus, strain $\mathrm{A} / \mathrm{PR} / 8 / 34$ was obtained from Charles River Laboratories (Horsham, USA). Rhinovirus type 14, strain 1059 (ATCC VR-284) was obtained from the American Type Culture Collection (Manassas, USA). The Madin-Darby canine kidney cell line (MDCK, ATCC CCL-34) and the H1-HeLa cell line (ATCC CRL-1658) were also obtained from the American Type Culture Collection.

\section{Test mask}

The test mask is an N95-rated (16) respiratory face mask comprised of the following layers, from outer to inner (Figure 2): an outer layer constructed of hydrophobic non-woven polypropylene that prevents external moisture from entering the mask material, followed by two layers of melt-blown non-woven polypropylene that capture oil and non-oil based particles through four key mechanisms. These include: (I) inertial impaction; (II) interception; (III) diffusion; and (IV) electrostatic attraction (16). The next layer is a modacrylic support layer that provides rigidity and adds thickness to the mask, giving it more structure and adding to the feel of comfort. The innermost layer is another hydrophobic non-woven polypropylene layer which minimizes moisture within the mask from entering the mask material and adversely impacting filtration efficiency. The mask samples were supplied to INSPEC Certification Services (Greater Manchester, UK), and Nelson Laboratories (Salt Lake City, USA) by Innosparks Pte Ltd. (Singapore) for a portion of the testing, while RB (China) provided mask samples to Microbac Laboratories (Sterling, USA) for additional testing.

\section{Assessment of influenza A virus and rbinovirus type 14 penetration}

An aerosol filtration test apparatus (Figure 3) assembled at Microbac per modified ASTM F2101-14 (12) was used for the influenza and rhinovirus penetration study. Test masks 
A

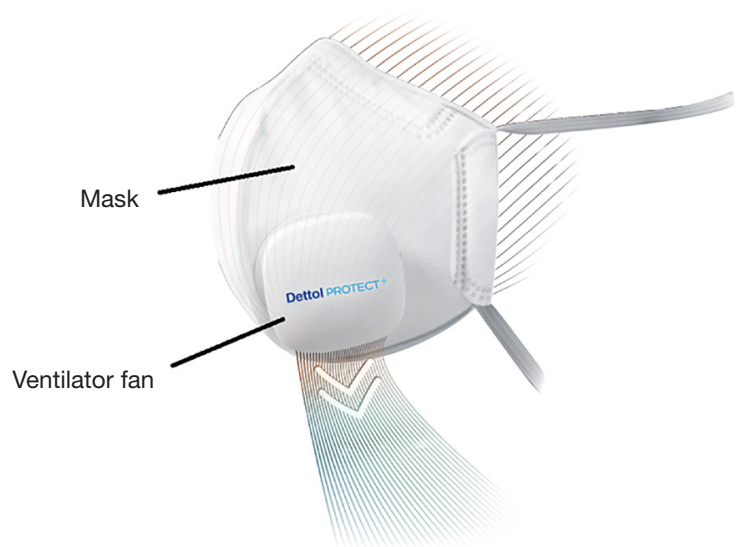

B

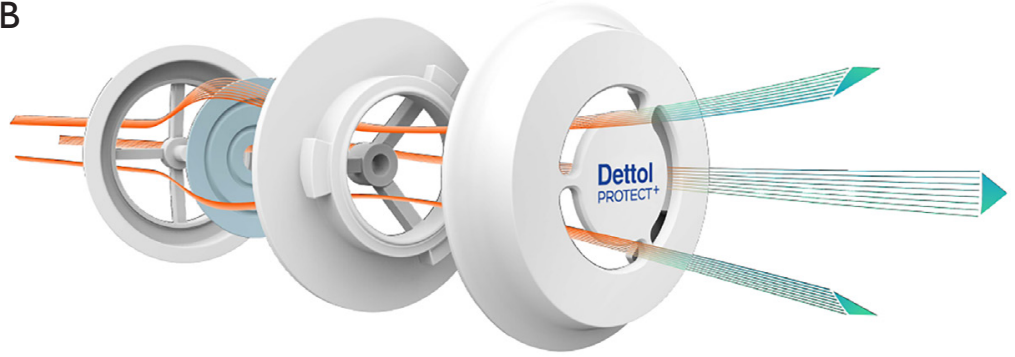

Figure 1 Schematic representation of the N95 test mask, the features designed to enhance wearer comfort, and the permitted airflows. (A) Airflow through the test mask during an exhalation; (B) detail of Smart Valve (located beneath the ventilator fan) showing the permitted air flow from inside to outside of the mask.

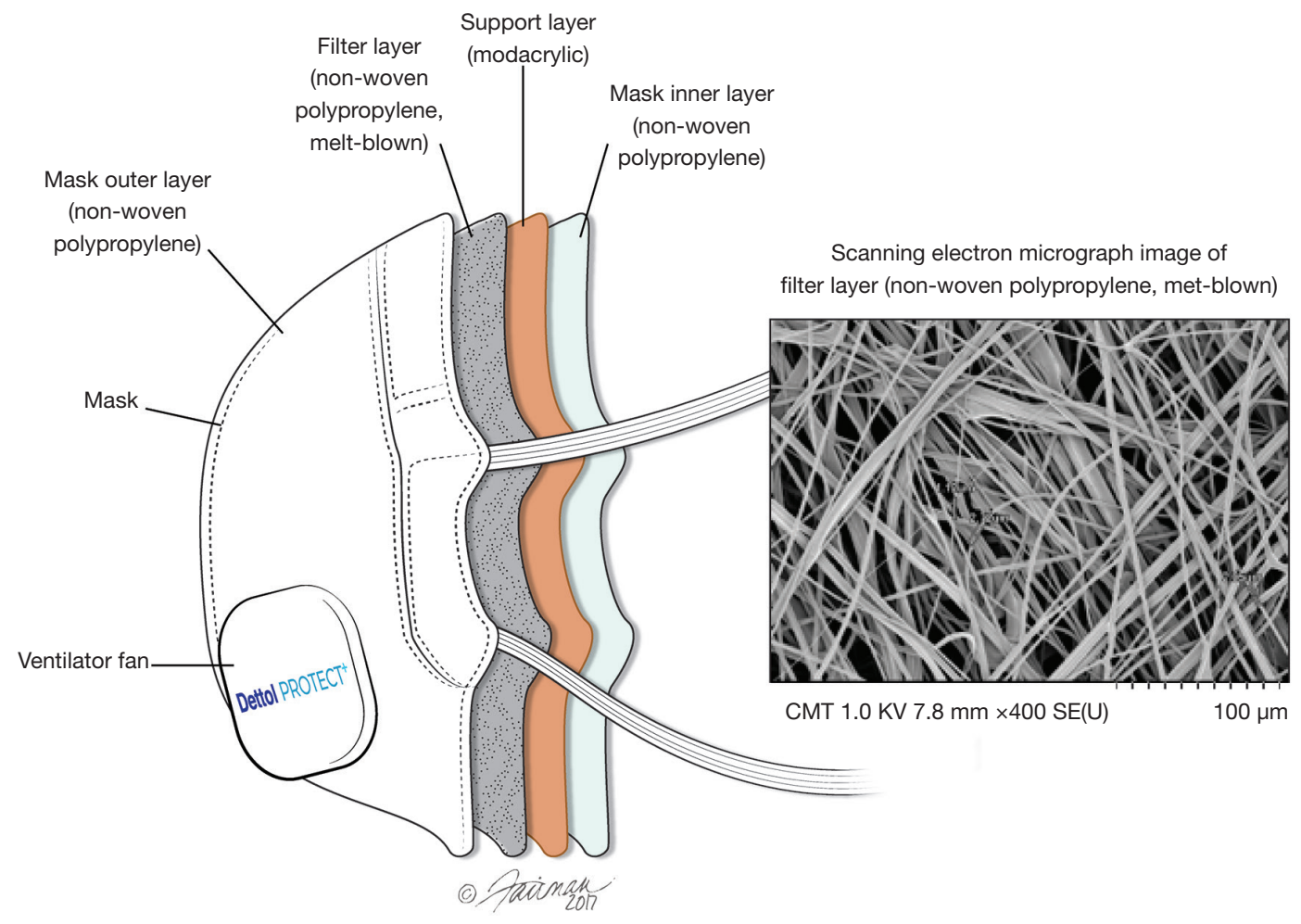

Figure 2 Schematic of the test mask showing the various layers. 
(the mask with operating Micro Ventilator, the mask with operating Smart Valve but without Micro Ventilator, or the mask with the Smart Valve covered/sealed) were placed between upstream and downstream chambers. The virus filtration efficiency test was performed in triplicate $(\mathrm{N}=3)$. For each run, a six-jet Collison nebulizer (Mesa Labs, Butler, USA) was filled with a measured amount of virus suspended in $0.1 \times$ Minimum Essential Medium (MEM) and the virus was aerosolized and delivered into the upstream chamber using high-pressure air. A downstream vacuum was turned on to create an air flow $(28.3 \mathrm{~L} / \mathrm{min})$ through the mask that was intended to mimic human breathing (17). After the delivery of the aerosol, the upstream air pressure was turned off and the downstream vacuum pump was left on for another minute to pull residual aerosol from the chambers into the one-stage Andersen sampler. Virus aerosol that passed through the mask was captured on a Petri dish containing semi-solid medium ( $5 \%$ gelatin/minimal essential medium). The collected sample was liquefied at $36 \pm 2{ }^{\circ} \mathrm{C}$ for approximately $10 \mathrm{~min}$. The resulting samples were divided into separate portions for ribonucleic acid (RNA) extraction and for infectivity assays (18).

Viral infectivity was measured on the basis of cytopathic effect (CPE) generated in MDCK cells (for influenza virus) and H1-HeLa cells (for rhinovirus). For the infectivity assay, a ten-fold dilution series of the samples collected as described above was prepared in a dilution medium. The sample dilutions were then inoculated onto the host cells. After 4-9 days of incubation, the CPE was scored under a phase-contrast light microscope. Viral titers were calculated in units of $\log _{10} 50 \%$ tissue culture infectious doses $\left(\mathrm{TCID}_{50}\right)$ per $\mathrm{mL}$ according to Spearman-Kärber (19).

For the qRT-PCR assay, RNA was extracted using a Qiagen QIAamp ${ }^{\circledR}$ Viral RNA Mini kit following the manufacturer's instructions. The RNA was analyzed using primers and probes specific to each virus. For influenza H1N1 virus, the forward primer was 5'-GAC CRA TCC TGT CAC CTC TGA C, the reverse primer was 5'-AGG GCA TTY TGG ACA AAC GTC TAA, and the probe was 5'-(FAM) TGC AGT CCT CGC TCA CTG GGC ACG (BHQ). For rhinovirus 14, the forward primer was 5'-GAG GTG TGC TGT GTG CTA CT and the reverse primer was 5'-GAC TTG GTT GGC GTG TTG AC.

\section{Assessment of S. aureus and bacteriophage $\Phi \times 174$ penetration}

Bacterial and phage filtration efficiencies for the masks without
Micro Ventilator were determined at Nelson Laboratories per EN 14683:2014 (14) and ASTM F2101-07 (13), respectively. The purpose of this testing was to assess the filtration efficiency of the filter material used in the test mask (Figure 2).

The bacterial filtration efficiency test compared the upstream bacterial control counts to downstream counts (i.e., counts attributed to passage of bacteria through the face mask). A suspension of $S$. aureus was aerosolized using a six-jet Collison nebulizer and delivered to the face mask $(\mathrm{N}=5$ replicate measurements) at a constant flow rate $(28.3 \mathrm{~L} / \mathrm{min})$ and challenge delivery $\left[1.7-2.7 \times 10^{3}\right.$ colony forming units (CFU)] with a mean particle size (MPS) of $3.0 \pm 0.3 \mu \mathrm{m}$. The aerosolized droplets were drawn through a six-stage Andersen sampler for collection.

The viral filtration efficiency test compared the upstream bacteriophage control counts to downstream counts (i.e., counts attributed to passage of bacteriophage through the face mask). A suspension of bacteriophage $\Phi X 174$ was aerosolized using a six-jet Collison nebulizer and delivered to the face mask ( $\mathrm{N}=5$ replicate measurements) at a constant flow rate $(28.3 \mathrm{~L} / \mathrm{min})$ and challenge delivery $\left[1.1-3.3 \times 10^{3}\right.$ plaque forming units (PFU)] with a MPS of $3.0 \pm 0.3 \mu \mathrm{m}$. The aerosolized droplets were drawn through a six-stage Andersen sampler for collection.

\section{Assessment of paraffin oil and sodium chloride penetration}

Filter penetration by the paraffin oil method for the test masks with operating Micro Ventilator was evaluated at INSPEC Certification Services per EN 149:2001 + A1:2009 (15) using a modified Phoenix SG-20 aerosol generator with detection using a photometer. The purpose of this evaluation was to provide evidence that the test mask configured with each of the features designed to enhance comfort would satisfy the requirements of this Standard. Per the Standard, the median diameter of the generated particles must be $0.6 \mu \mathrm{m}$ (15). Three replicates of the mask were evaluated under "as received", "simulated wearing", and "mechanical strength and temperature conditioning" conditions per the Standard (15). The methodology is equivalent to that specified by the National Institute for Occupational Safety and Health (NIOSH) for rating masks. For instance, an N95-rated mask removes $95 \%$ of a $0.3-\mu m$ (mass median aerodynamic diameter) particle sodium chloride aerosol and is not resistant to oils (16).

\section{Statistical comparisons}

Single-factor analysis of variance (ANOVA) was used to 


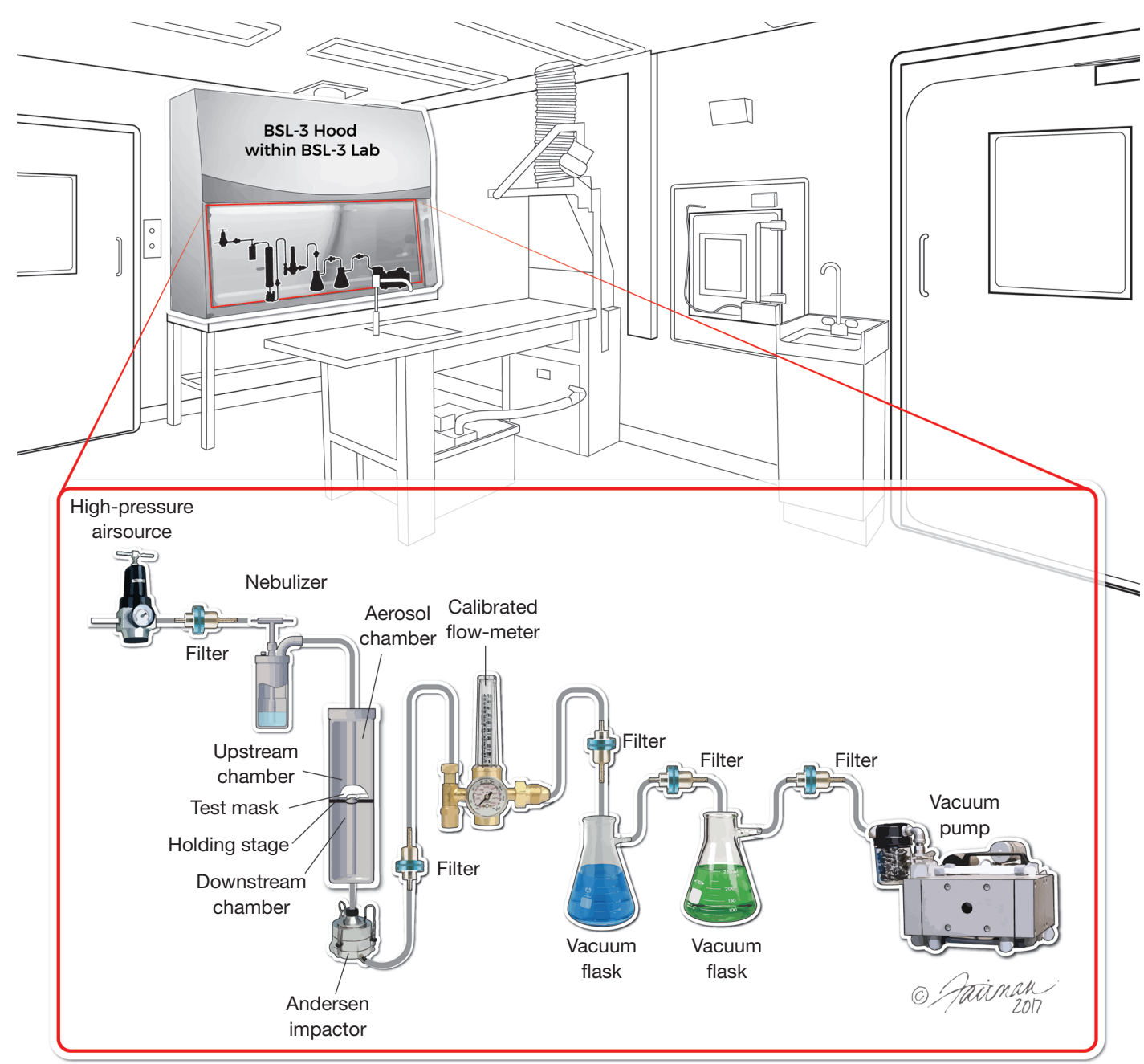

Figure 3 Test set up for the influenza A virus and rhinovirus type 14 penetration studies.

determine the statistical significance of differences in the mean filtration efficiency values obtained for different test microorganisms, or in particulates testing, the differences between "as received" and other conditions (see above). A $\mathrm{P}$ value $<0.05$ was considered to be statistically significant. The significance of differences among mean values for different test mask configurations for a given virus was evaluated using a two-tailed $t$-test.

\section{Results}

The efficiencies of various configurations of the test mask (masks with operational or nonoperational ventilation fans or masks with sealed Smart Valves) for filtration of pathogens and surrogate air pollutants, including respiratory viruses, bacteria, bacteriophage, and particulates, were determined empirically per the requirements of the relevant Standards (12-15).

\section{Assessment of influenza A virus and rbinovirus penetration}

The ability of the test mask to provide user protection against airborne pathogenic viruses was assessed using the human respiratory viruses, influenza $\mathrm{A}(\mathrm{H} 1 \mathrm{~N} 1)$ virus and rhinovirus 14 per ASTM F2101-14 (12). The viruses evaluated differ with respect to size and envelope status. Influenza virus is a member of the Orthomyxoviridae family and is a relatively large $(80-120 \mathrm{~nm})$ enveloped virus, while the rhinovirus is a member of the Picornaviridae family and is a small $(27-30 \mathrm{~nm})$ non-enveloped virus (20). It might be expected, based purely on particle size, that the rhinovirus would represent a greater challenge for a filter mask than the influenza virus, but other 
Table 1 Efficiency of test mask configurations for filtration of influenza A virus and rhinovirus 14

\begin{tabular}{|c|c|c|c|c|}
\hline Test mask configuration ${ }^{\star}$ & \multicolumn{2}{|c|}{ Influenza A (H1N1) virus (Strain A/PR/8/34) } & \multicolumn{2}{|c|}{ Rhinovirus Type 14 (Strain 1059) } \\
\hline 1 & $99.7 \% \pm 0.5 \%$ & $100 \% \pm 0.0 \%$ & $99.6 \% \pm 0.5 \%$ & $97.0 \% \pm 5.2 \%$ \\
\hline 2 & $99.9 \% \pm 0.1 \%$ & $99.3 \% \pm 1.0 \%$ & $99.8 \% \pm 0.2 \%$ & $99.5 \% \pm 0.9 \%$ \\
\hline 3 & $99.6 \% \pm 0.5 \%$ & $98.9 \% \pm 1.8 \%$ & $99.9 \% \pm 0.2 \%$ & $99.6 \% \pm 0.5 \%$ \\
\hline
\end{tabular}

This work was performed by Microbac Laboratories (Sterling, USA). ${ }^{*}$ Configurations: 1 , test mask with Smart Valve and without Micro Ventilator; 2, test mask with covered/sealed Smart Valve and without Micro Ventilator; 3, test mask with Smart Valve and operating Micro Ventilator. $\dagger$, mean \pm standard deviation $(\mathrm{N}=3)$.

Table 2 Efficiency of the test mask without Micro Ventilator for filtration of Staphylococcus aureus and bacteriophage ФX174

\begin{tabular}{lcc}
\hline \multirow{2}{*}{ Replicate } & \multicolumn{2}{c}{$\%$ Filtration assessed by infectivity } \\
\hline Replicate 1 & Staphylococcus aureus & Bacteriophage $\Phi X 174$ \\
Replicate 2 & $>99.9 \%$ & $99.6 \%$ \\
Replicate 3 & $>99.9 \%$ & $99.8 \%$ \\
Replicate 4 & $99.7 \%$ & $>99.9 \%$ \\
Replicate 5 & $99.8 \%$ & $99.8 \%$ \\
Mean \pm SD (N=5 replicates) & $>99.9 \%$ & $99.5 \%$ \\
\hline
\end{tabular}

This work was performed by Nelson Laboratories (Salt Lake City, USA). *, For the purpose of averaging and statistical analysis, values indicated as $>99.9 \%$ were treated as $99.9 \%$. SD, standard deviation.

considerations apply, as discussed below.

The results of the virus filtration efficiency study (Table 1) indicate that regardless of configuration or surrogate virus evaluated, $\geq 99.6 \%$ (range, $99.6-99.9 \%$ ) of infectious virus was excluded by the test mask. Filtration efficiency determined by RT-PCR (which determines presence of both infectious and non-infectious virus) was found to range from $98.9 \%$ to $100 \%$. In most cases, greater variability was observed in these replicate filtration efficiency measurements based on RT-PCR, compared with the infectivity endpoint (Table 1). No statistically significant differences were observed when these data were analyzed by either influenza virus or rhinovirus for a given mask configuration, or by mask configuration for either one of the viruses.

\section{Assessment of S. aureus and bacteriophage $\Phi \times 174$ penetration}

Additional characterization of the ability of the test mask without Micro Ventilator to provide user protection against airborne pathogens was afforded by examination of the filtration efficiency for Staphylococcus aureus and the bacteriophage $\Phi$ X174 per ASTM F2101-7 (13). These bacterial and viral surrogates differ greatly in size $(\sim 2,000 \times 500 \mathrm{~nm}$ for $S$. aureus $v s . \sim 34 \mathrm{~nm}$ for the bacteriophage). Due to their differing sizes, it might be expected that the bacteriophage would represent a greater challenge for a filter mask than the bacterium, although other considerations apply, as discussed below.

The result of the virus filtration efficiency and bacteria filtration efficiency studies (Table 2) indicate that regardless of the surrogate pathogen evaluated, $\geq 99.5 \%$ (range, 99.5-99.9\%) of microbial agents was excluded by the mask. No statistically significant differences were observed when these data were analyzed by surrogate pathogen for the test mask configuration evaluated.

\section{Assessment of paraffin oil and sodium chloride penetration}

The ability of the test mask with operational Smart Valve and Micro Ventilator fan to provide protection against airborne particulates was assessed per EN 149:2001 + 
Table 3 Efficiency of the test mask with Micro Ventilator for filtration of particulates

\begin{tabular}{lcc}
\hline \multirow{2}{*}{ Conditioning of mask per EN149 } & \multicolumn{2}{c}{$\%$ Penetration (mean \pm SD, N=3) } \\
\cline { 2 - 3 } As received & Sodium chloride (solid) & Paraffin oil (liquid) \\
Simulated wearing & $99.9 \% \pm 0.0 \%$ & $99.7 \% \pm 0.0 \%$ \\
Mechanical strength and temperature conditioning & $99.9 \% \pm 0.0 \%^{*}$ & $99.4 \% \pm 0.1 \%{ }^{*}$ \\
Overall $(\mathrm{N}=9)$ & $99.9 \% \pm 0.0 \%$ & $99.6 \% \pm 0.1 \%$ \\
\hline
\end{tabular}

This work was performed by INSPEC (Greater Manchester, UK). *, significantly different from the "as received" value by two-tailed $t$-test. $\mathrm{SD}$, standard deviation.

A1:2009 (15) using paraffin oil to model liquid particulates and sodium chloride to model solid particulates. The results for various conditioning categories required by the Standard are displayed in Table 3. The efficiency for exclusion of sodium chloride was $99.9 \%$, regardless of the conditioning ("as received", "simulated wearing", or "mechanical strength and temperature conditioning"). The efficiency for paraffin oil ranged from $99.3 \%$ to $99.7 \%$. Although a statistically significant difference between "as received" and "simulated wearing" testing was identified for both sodium chloride and paraffin oil $(\mathrm{P}<0.05)$, the requirements for the Standard were met, including penetration limits as well as breathing resistance (a measure of comfort; data not shown).

\section{Discussion}

Protection of individuals from environmental pollutants, including pathogens, allergens, and fine particulates $\left(\mathrm{PM}_{2.5}\right)$, can be achieved, in part, through use of personal protective devices such as respiratory face masks. The use of face masks for this purpose is more common in certain geographical regions, such as China and India, where population densities are higher, and the residents are more likely to be chronically exposed to $\mathrm{PM}_{2.5}$ levels exceeding annual World Health Organization Air Quality Guidelines $\left(<10 \mu \mathrm{g} / \mathrm{m}^{3}\right)(9)$.

The compliance of use of respiratory face masks should be facilitated by features such as the Smart Valve and operational Micro Ventilator (Figure 1), which are designed to aid in the evacuation of exhaled gases from the interior of the mask (11). The enhancement of user comfort may be measured quantitatively through assessment of gas content in the dead space of the mask and systemic and facial thermoregulation (11). Goh et al. [Goh YTD, Mun MW, Lee WLJ, et al. A randomised clinical trial to evaluate the safety, fit, comfort of a novel N95 mask in children. (submitted for publication)] found, in a clinical study in children aged 7-14 years, that wearing this test mask without Micro Ventilator increased the end-tidal $\mathrm{CO}_{2}$ $\left(\mathrm{ETCO}_{2}\right)$ and fractional concentration of inspired $\mathrm{CO}_{2}$ $\left(\mathrm{FICO}_{2}\right)$, compared to children without masks at rest and during brisk walking. In contrast, wearing the mask with operational Micro Ventilator brought $\mathrm{FICO}_{2}$ levels for both activities closer to baseline levels obtained in children not wearing the mask. Computational Fluid Dynamics (CFD) simulation experiments conducted in adult subjects have demonstrated that the introduction of a ventilation fan to the N95 mask is a feasible option for reducing $\mathrm{CO}_{2}$ accumulation in the dead space of the mask and also for controlling the temperature of the air within the dead space $(21,22)$. The clinical study [Goh YTD, Mun MW, Lee WLJ, et al. A randomised clinical trial to evaluate the safety, fit, comfort of a novel N95 mask in children. (submitted for publication)] confirmed the earlier CFD studies indicating reduction of $\mathrm{CO}_{2}$ in the dead space of the mask with operational ventilator fan. Furthermore, CFD studies performed in adult subjects have demonstrated reduction in heat, $\mathrm{CO}_{2}$, and moisture build-up within N95 masks configured with operational ventilator fans $(21,22)$. Moisture build-up in N95 masks used in high humidity atmospheres has been shown to reduce filtration efficiency of the masks for Ebola-Makona virus (23).

Mask inhalation and exhalation breathing resistance requirements are addressed in the European Respiratory Protection certification EN149:20001 + A1:2009 (15). These requirements were met by the test mask with operational Smart Valve and Micro Ventilator fan. Additional evidence that the Smart Valve and Micro Ventilator fan results in a mask that provides acceptable breathing resistance characteristics (inhalation and exhalation) is the fact that the test mask was awarded an N95 rating by 
NIOSH. Testing for satisfaction of this rating includes evaluation of inhalation and exhalation resistance (16). The use of respiratory face masks with operational ventilation fans is therefore useful both from a comfort-enhancement perspective as well as for providing optimal filtration efficiency.

Ideally, any features added to a respiratory protective device solely for the purpose of enhancing wearer comfort should not adversely impact the primary function of the device, which is to filter airborne particulates and infectious agents from the contaminated air. In the present study, we have assessed the efficiency of the test mask for filtration of surrogate pathogens (bacteria and respiratory viruses) and pollutants. Various configurations of the mask (Table 1) were challenged, including the mask with operating Micro Ventilator, the mask with operating Smart Valve but without Micro Ventilator, and the mask with the Smart Valve covered/sealed. The latter configuration would be considered "best case" for excluding experimentally aerosolized contaminants [surrogate pathogens/particulates such as $\left.\mathrm{PM}_{2.5}(16,24)\right]$, while the fully operational Micro Ventilator would be considered "worst case" for this purpose. For instance, a poorly functioning Smart Valve may allow environmental contaminants into the interior of the mask, defeating the purpose of the mask as a filtration device.

A filtration efficiency value for pathogens (influenza A, rhinovirus 14 , bacteriophage $\Phi \times 174$, and S. aureus) of $>99.6 \%$ was achieved by the test mask, regardless of configuration tested. This value reflected the ability of the mask to exclude infectious agents, including respiratory viruses. Similar, albeit more variable, results were obtained when genomic copies of influenza A virus and rhinovirus were monitored rather than infectious virus. The filtration efficiency of the test mask for surrogate pathogens was similar, regardless of the challenge microbial agents' size (ranging from 27-30 nm for bacteriophage and rhinoviruses to $2,000 \mathrm{~nm}$ for $S$. aureus).

This similarity in filtration efficiency for different size microbes may reflect, in large part, the fact that the challenge was in the form of aerosol particles with MPS of $\sim 3.0 \mu \mathrm{m}$. The particle size used was that stipulated in the relevant Standard (ASTM F2101) $(12,13)$ and reflects the concern over transmission of infectious agents through fine aerosols, as has been demonstrated for influenza virus (25-27) and smallpox (variola) virus (28). The potential role of fine aerosols in transmission of a variety of viruses, such as measles, influenza, rhinoviruses, severe acute respiratory syndrome coronavirus (SARS-CoV), Middle East respiratory syndrome coronavirus (MERS-CoV), hantavirus (Sin Nombre virus), rabies, pox and Ebola viruses has been reviewed $(7,8)$. For example, Lindsley et al. (27) measured the content of influenza virus in aerosol particles from human coughs, reporting that $35 \%$ of the influenza RNA detected was contained in particles $>4 \mu \mathrm{m}$ in aerodynamic diameter, whereas $23 \%$ were contained in particles of $1-4 \mu \mathrm{m}$ diameter and $42 \%$ were in particles $<1 \mu \mathrm{m}$ in diameter, indicating that the majority of the viral RNA from human coughs was within the respirable size range. Also, aerosols generated by coughing patients infected with Mycobacterium tuberculosis were between the range of $0.65-4.7 \mu \mathrm{m}$ in diameter (29).

The reduction of viable H1N1 influenza conferred by five brands of N95 face mask was found to range from $96.3 \%$ to $99.995 \%$ by Harnish et al. (30). The nearly three $\log _{10}$ reduction in penetration of viruses observed in the current study and in other studies using N95 face masks represents an improvement over the 2.8-fold reduction in penetration of genomic copies for influenza virus challenged via a fine $(<5 \mu \mathrm{m})$ aerosol obtained during testing of a surgical mask (25). The latter results confirm previous observations of the limited value of surgical masks for filtering fine aerosols containing infectious agents and particulates (31).

The filtration efficiency studies performed on the test mask were based on methodologies described in the various international Standards followed (i.e., ASTM F2101 and EN149:20001 + A1:2009). The methods described within these Standards are based on the following assumptions: (I) that infections that are typically transmitted through the respiratory route are in the form of virus-containing aerosols originating from the source (e.g., infected patient's respiratory secretions) and not individual monodispersed viral particles. For instance, influenza virus, particles of which are only about $100 \mathrm{~nm}$ in diameter, has been found in healthcare centers predominantly in aerosolized respiratory fluid droplets having aerodynamic diameters of $4 \mu \mathrm{m}$ or larger (32); further assumptions are: (II) that the testing of penetration of model pathogens and particulates through a mask can be used to determine acceptable performance against a variety of pathogens/particulate types; and (III) the ASTM F2101 Standard does not require pre-stressing or conditioning of the mask, and it must be acknowledged that degradation of the mask material by physical, chemical, or thermal stresses could negatively impact the filtration efficiency of the mask (12). The ASTM Standard also does not address breathability characteristics of the mask, although this is addressed by the EN149:20001 + A1:2009 
Standard and the N95 testing performed by NIOSH as part of their rating process.

Masks are often used in healthcare settings, where they may be employed to limit the spread of respiratory infections from infected patients to healthcare workers (33). In these cases, the masks are worn as personal protective equipment by healthcare workers. Results of the increased efficiency of N95-rated masks such as that tested in our study suggest that such masks should be used, rather than surgical masks, for this purpose. The relatively greater filtration efficiency of N95-rated face masks relative to surgical masks demonstrated in laboratory studies has not, however, translated into significant differences in protection of healthcare workers in controlled studies (34-36) which could be due to lack of fitting information provided in these studies.

Given the cultural acceptability of wearing masks in public in countries such as China, consumers use masks for prevention of exposure to infectious agents (during influenza, SARS-CoV, and MERS-CoV outbreaks). Will such face masks protect family members, healthcare workers and other patients by having the source (infected) patient wear the mask? On theoretical grounds, a face mask with a Smart Valve should allow unfiltered exhaled air to exit the mask. If this occurs, having an infected patient wear such a mask may not protect other patients and healthcare workers. As a next step it would be prudent, using methods such as those used by Milton et al. (25), to assess the passage of virus in the reverse direction (i.e., from the interior of the mask to the exterior through the Smart Valve) in order to provide assurance to both healthcare professionals and public at large. The development of a Micro Ventilator containing a suitable filter as part of the Smart Valve might confer the necessary filtration capabilities to a mask intended for such purposes.

Filtration of fine non-infectious particulates is also an important aspect of face masks such as the test mask. The anticipated health benefits associated with this function include reduction in the inhaled burden of allergens and toxic pollutants (e.g., $\mathrm{PM}_{2.5}$ ). The wearing of face masks has been demonstrated to provide cardiopulmonary health benefits in studies involving both healthy and comorbid clinical subjects in Beijing $(37,38)$. Currently, a study is underway which is investigating the interventional role of the test mask in cardiovascular events emerging post-exposure to fine particulates $\left(\mathrm{PM}_{2.5}\right)$ in healthy American subjects (39). The filtration efficiency of the test mask in the present study was $>99.9 \%$ for sodium chloride and $>99.3 \%$ for paraffin oil. The latter result indicates that the filter material used in the test mask displays oil resistance. As such, the test mask would be expected to provide filtration efficiency for combustion products (40) in addition to the efficiency demonstrated for sodium chloride (a surrogate for allergens and pollutants such as $\mathrm{PM}_{2.5}$ ). As discussed above for filtration of infectious agents, comparative testing of N95 facepiece respirators and surgical masks has shown that surgical masks are less effective for filtration of sodium chloride aerosols (41).

Any increased benefits of N95 facepiece respirators such as the test mask over surgical masks are likely dependent upon the ergonomic fit of the mask to the wearer's face. This is because in the absence of a tight fit, inward leakage would be expected to dominate over filter penetration as the predominant mode of entry of particulates/aerosols containing infectious agents into the mask, regardless of the type of mask (30-32,41). A controlled clinical study failed, however, to reveal a significant difference in protection of healthcare workers using fit-tested $v s$. nonfit-tested N95 masks (42). As with other clinical trials of this type mentioned above, the study may not have been powered sufficiently to detect any differences. In addition, compliance was not complete in the study (masks were worn $68-79 \%$ of the time) and the degree of leakage in the not-fit-test arm was not assessed. Judging from the low rate of fit-test failures observed in the fit-test arm (1.1\%), the actual amount of leakage that occurred in the non-fit-tested arm may have been very low (i.e., the lack of fit testing likely did not correspond to leaky masks in that treatment arm) (42). Therefore, the test mask used in this study is targeted for improving comfort, and therefore compliance, and may potentially deliver positive health benefits both in healthy and comorbid populations.

\section{Conclusions}

The results generated by three independent testing laboratories demonstrate $>99.7 \%$ efficiency of the test mask for the protection of users from influenza A virus, rhinovirus 14 , and $S$. aureus, and $>99.3 \%$ effective for surrogate particulates such as paraffin oil and sodium chloride. The mask provides protection against both small- and large-size pathogens and the surrogate particulate results suggest that the mask should also be effective at excluding pollutants such as $\mathrm{PM}_{2.5}$ and allergens. Importantly, the mask appears to be highly efficient for filtration of pathogens including influenza and rhinoviruses and fine particulates present in aerosols which represent a greater challenge for many 
types of dental and surgical masks. This renders these individual-use masks an improvement over the former types of masks for protection against a variety of environmental contaminants including pathogens such as influenza and rhinoviruses.

\section{Acknowledgements}

We thank INSPEC (Greater Manchester, UK), Microbac (Sterling, VA), and Nelson Laboratories (Salt Lake City, Utah) for performing the tests. The funding for the testing described herein was provided by RB. The critical review and feedback provided by Jerome Lee (Innosparks Pte Ltd., Singapore), and John Creek, Wil Garcia, Joanne Hunt, and Louise Rowe from RB, is gratefully acknowledged.

\section{Footnote}

Conflicts of Interest: MK Ijaz is employed by RB, which provided funding for the independent evaluation of the test mask. The other authors have no financial interest in RB or the test mask under investigation. The authors (other than MK Ijaz) declare no financial conflict of interest in this work.

\section{References}

1. World Health Organization. Burden of disease from the joint effects of Household and Ambient Air Pollution for 2012. WHO Technical Report. Available online: http:// www.who.int/phe/health_topics/outdoorair/databases/AP_ jointeffect_BoD_results_March2014.pdf

2. Pope CA 3rd, Burnett RT, Thun MJ, et al. Lung cancer, cardiopulmonary mortality, and long-term exposure to fine particulate air pollution. JAMA 2002;287:1132-41.

3. Hoek G, Krishnan RM, Beelen R, et al. Long-term air pollution exposure and cardio- respiratory mortality: a review. Environ Health 2013;12:43.

4. Yang G, Wang Y, Zeng Y, et al. Rapid health transition in China, 1990-2010: findings from the Global Burden of Disease Study 2010. Lancet 2013;381:1987-2015.

5. Rohde RA, Muller RA. Air Pollution in China: Mapping of Concentrations and Sources. PLoS ONE 2015;10:e135749.

6. Guan WJ, Zheng XY, Chung KF, et al. Impact of air pollution on the burden of chronic respiratory diseases in China: time for urgent action. Lancet 2016;388:1939-51.

7. Ijaz MK, Zargar B, Wright KE, et al. Generic aspects of the airborne spread of human pathogens indoors and emerging air decontamination technologies. Am J Infect Control 2016;44:S109-20.

8. Sattar S, Bhardwaj N, Ijaz M. Airborne viruses. In: Yates M, Nakatsu C, Miller R, et al., editors. Manual of environmental microbiology. 4th edition. Washington (DC): ASM Press, 2016:3.2.7-1-24.

9. Brook RD, Newby DE, Rajagopalan S. The Global Threat of Outdoor Ambient Air Pollution to Cardiovascular Health: Time for Intervention. JAMA Cardiol 2017;2:353-4.

10. Rohde RA, Muller RA. Air Pollution in China: Mapping of Concentrations and Sources. PLoS One 2015;10:e0135749.

11. Roberge RJ, Kim JH, Coca A. Protective facemask impact on human thermoregulation: an overview. Ann Occup Hyg 2012;56:102-12.

12. ASTM F2101-14 Standard test method for evaluating the bacterial filtration efficiency (BFE) of medical face mask materials, using a biological aerosol of Staphylococcus aureus. American Society for Testing and Materials, 2014.

13. ASTM F2101-07 Standard test method for evaluating the bacterial filtration efficiency (BFE) of medical face mask materials, using a biological aerosol of Staphylococcus aureus. American Society for Testing and Materials.

14. BS EN 14683:2014 Medical face masks. Requirements and test methods. European Committee for Standardization. BSI, 2014.

15. BS EN 149:2001 + A1:2009. Respiratory protective devices - Filtering half masks to protect against particles Requirements, testing, marking. European Committee for Standardization. BSI, 2001.

16. Brosseau L, Ann RB. N95 respirators and surgical masks. Centers for Disease Control and Prevention, 2009. Available online: https://blogs.cdc.gov/niosh-scienceblog/2009/10/14/n95/

17. Borkow G, Zhou SS, Page T, et al. A novel anti-influenza copper oxide containing respiratory face mask. PLoS One 2010;5:e11295.

18. Ijaz MK, Karim YG, Sattar SA, et al. Development of methods to study the survival of airborne viruses. J Virol Methods 1987;18:87-106.

19. Finney DJ. Statistical methods in biological assay. 3rd edition. New York: McMillan Co., Inc., 1978:394-401.

20. Jiang P, Liu Y, Ma HC, et al. Picornavirus morphogenesis. Microbiol Mol Biol Rev 2014;78:418-37.

21. Birgersson E, Tang EH, Lee WL, et al. Reduction of Carbon Dioxide in Filtering Facepiece Respirators with an Active-Venting System: A Computational Study. PLoS 
One 2015;10:e0130306.

22. Zhang X, Li H, Shen S, et al. An Improved FFR Design with a Ventilation Fan: CFD Simulation and Validation. PLoS One 2016;11:e159848.

23. Nikiforuk AM, Cutts TA, Theriault SS, et al. Challenge of Liquid Stressed Protective Materials and Environmental Persistence of Ebola Virus. Sci Rep 2017;7:4388.

24. Air Particles chart. AirPurifiers America. Available online: https://www.air-purifiers-america.com/pages/air-particles-chart

25. Milton DK, Fabian MP, Cowling BJ, et al. Influenza virus aerosols in human exhaled breath: particle size, culturability, and effect of surgical masks. PLoS Pathog 2013;9:e1003205.

26. Harnish DA, Heimbuch BK, Balzli C, et al. Capture of $0.1-\mu \mathrm{m}$ aerosol particles containing viable $\mathrm{H} 1 \mathrm{~N} 1$ influenza virus by N95 filtering facepiece respirators. J Occup Environ Hyg 2016;13:D46-9.

27. Lindsley WG, Blachere FM, Thewlis RE, et al. Measurements of airborne influenza virus in aerosol particles from human coughs. PLoS One 2010;5:e15100.

28. Milton DK. What was the primary mode of smallpox transmission? Implications for biodefense. Front Cell Infect Microbiol 2012;2:150.

29. Wei J, Li Y. Airborne spread of infectious agents in the indoor environment. Am J Infect Control 2016;44:S102-8.

30. Harnish DA, Heimbuch BK, Husband M, et al. Challenge of N95 filtering facepiece respirators with viable H1N1 influenza aerosols. Infect Control Hosp Epidemiol 2013;34:494-9.

31. Oberg T, Brosseau LM. Surgical mask filter and fit performance. Am J Infect Control 2008;36:276-82.

32. Lindsley WG, Green BJ, Blachere FM, et al. Sampling and characterization of bioaerosols. In: NIOSH Manual of Analytical Methods (NMAM), 5th Edition. Available online: https://www.cdc.gov/niosh/nmam/pdf/chapter-ba.pdf

33. Centers for Disease Control and Prevention. Prevention strategies for seasonal influenza in healthcare settings. Available online: https://www.cdc.gov/flu/professionals/ infectioncontrol/healthcaresettings.htm

Cite this article as: Zhou SS, Lukula S, Chiossone C, Nims RW, Suchmann DB, Ijaz MK. Assessment of a respiratory face mask for capturing air pollutants and pathogens including human influenza and rhinoviruses. J Thorac Dis 2018;10(3):2059-2069. doi: 10.21037/jtd.2018.03.103
34. Loeb M, Dafoe N, Mahony J, et al. Surgical mask vs N95 respirator for preventing influenza among health care workers: a randomized trial. JAMA 2009;302:1865-71.

35. MacIntyre CR, Wang Q, Seale H, et al. A randomized clinical trial of three options for N95 respirators and medical masks in health workers. Am J Respir Crit Care Med 2013;187:960-6.

36. Smith JD, MacDougall CC, Johnstone J, et al. Effectiveness of $\mathrm{N} 95$ respirators versus surgical masks in protecting health care workers from acute respiratory infection: a systematic review and meta-analysis. CMAJ 2016;188:567-74.

37. Langrish JP, Mills NL, Chan JK, et al. Beneficial cardiovascular effects of reducing exposure to particulate air pollution with a simple facemask. Part Fibre Toxicol 2009;6:8.

38. Langrish JP, Li X, Wang S, et al. Reducing personal exposure to particulate air pollution improves cardiovascular health in patients with coronary heart disease. Environ Health Perspect 2012;120:367-72.

39. United States National Library of Medicine. ClinicalTrials. gov. Particulate Matter, Blood Pressure, and the Sympathetic Nervous System (PM-SNS). Available online: https://clinicaltrials.gov/ct2/show/NCT03079843

40. Gao S, Kim J, Yermakov M, et al. Penetration of Combustion Aerosol Particles Through Filters of NIOSHCertified Filtering Facepiece Respirators (FFRs). J Occup Environ Hyg 2015;12:678-85.

41. Rengasamy S, Eimer BC, Szalajda J. A quantitative assessment of the total inward leakage of $\mathrm{NaCl}$ aerosol representing submicron-size bioaerosol through N95 filtering facepiece respirators and surgical masks. J Occup Environ Hyg 2014;11:388-96.

42. MacIntyre CR, Wang Q, Cauchemez S, et al. A cluster randomized clinical trial comparing fit-tested and nonfit-tested N95 respirators to medical masks to prevent respiratory virus infection in health care workers. Influenza Other Respir Viruses 2011;5:170-9. 